NBSIR 76-1051(R)

\title{
A Prototype Automated Test System for J52 Engine Fuel Controls
}

\section{Part 1. Hardware Systems Summary}

David W. Baker*

Alfred L. Koenig**

Victor Brame, Jr.*

Institute for Basic Standards*

Institute for Computer Sciences and Technology**

April 1976

Final

Prepared for

Naval Air Systems Command

Department of the Navy

Washington, D. C. 20361 



\section{A PROTOTYPE AUTOMATED TEST SYSTEM FOR J52 ENGINE FUEL CONTROLS PART 1. HARDWARE SYSTEMS SUMMARY}

David W. Baker*

Alfred L. Koenig**

Victor Brame, Jr.*

Institute for Basic Standards*

Institute for Computer Sciences and Technology**

April 1976

Final

\section{Prepared for}

Naval Air Systems Command

Department of the Navy

Washington, D. C. 20361

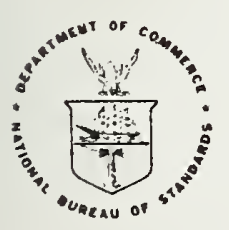

U.S. DEPARTMENT OF COMMERCE, Elliot L. Richardson, Secrotary James A. Baker, III, Under Secretary

Dr. Betsy Ancker-Johnson, Assistant Secretary for Scionce and Technology

NATIONAL BUREAU OF STANDARDS. Ernest Ambler, Acting Director 

Hardware subsystems are described which have been developed by NBS and added to a manually controlled test stand, CID Model 15730, and which together comprise the test system. Digital computer control is used which incorporates a vendor supplied real time software operating system, extended and adapted to the hardware subsystems by NBS. When applications software is complete, the system will be suitable for production testing of J52 engine fuel controls. Test parameters under computer control are shaft speed, burner air pressure and compressor inlet pressure, along with systems used solely for measurement of fuel control discharge and supply flowrates and eight fuel control pressures. The operator controls the test through a subsystem equipped with a CRT, a teletypewriter, and a set of backlighted display lamps. The hardware and software systems have been designed for multistand control, and hardware requirements for control. of up to five stands by one computer are discussed briefly.

Key Words: Automated test equipment; Automated test equipment for jet engine fuel controls; Digital computer controlled test equipment; Jet engine fuel control test equipment; Minicomputer applications; Minicomputer controlled test equipment; Supervisory control. 
1. Introduction

Page

2. Hardware Systems Overview

3. Systems Design

3.1 NC Speed Control

3.2 PB Pressure Control

3.3 PT2 Pressure Control

3.4 WF and WT Measuring Systems

3.5 Pressure Measuring Systems

3.6 Operator/Machine Interaction

3.7 Test Stand Control and Power Flow

3.8 Purge Air System

4. References

Appendix A. Five Stand Design

Appendix B. Primary Hardware Components 
1. J52 System Hardware Configuration 3

2. CID Model 15730 Test Stand Console With Prototype 4 Operator Control/Display Panel

3. J52 Computer System 6

4. NC Speed Control 7

5. $\mathrm{PB}$ Pressure Control 9

6. PT2 Pressure Control 12

7. WF and WT Measuring Systems 13

8. Pressure Measuring Systems 15

9. Operator Control/Display Panel 16

10. CRT and Lamp Display Panel 18

11. Pendant Station for Step Motor Manual Control 19

12. Test Stand Power Flow and Control Sequence 21

13. Purge Air Circuit and Interlock Locations 23

14. Power Flow to Automated Systems, Safety Interlocks 24

15. J52 System Auxiliary Racks 1 and $2 \quad 27$ 


\section{ACKNOWLEDGEMENTS}

The prototype test system has been developed and built under a program sponsored and supported by the Department of the Navy, Naval Air Systems Command, Code AIR5343, headed by Mr. Thomas Lyle. Participation and assistance rendered by Mr. William Haight, NBS Division 213.06, and Mr. John Hazzard, 213.04, in design of the Operator Panel; by Mr. Kenneth Benson and Mr. James Melvin, 213.06, during installation of the test stand and automation components: by Mr. Louis Palombo and Mr. James McNa11y, 650.01, for computer interface construction and hardware systems cabling; and by Miss Pat Bea11, 213.06, and Mrs. Susanne Bussard, 213.00, for manuscript typing is gratefully acknowledged. 
A prototype automated test system has been developed and bulli at th: National Bureau of Standards for use in the adjustment and calibration of J52 engine fuel controls. A manually operated production test stand, installed and operational at NBS, has been put under digital computer control by the addition of hardware subsystems, and by extension and adaptation of real-time operating system (RTOS) software. The stand, Model CID 15730, was built by Cox Instruments Division of the Lynch Corporation* and RTOS was supplied by Interdata Incorporated, the computer vendor. To complete the software system, application software suitable for production testing of J52 engine fuel controls will be needed. Such software has been designed but has not been written. Farlier documentation [1]** includes RTOS as extended and adapted by NBS and the design of the necessary application software.

The purpose of this report is to summarize the hardware systems in this prototype system from a general functional and design point of view. Some estimates of performance under computer control are included and these are subject to verification when complete application software is available. Design details covering the computer interfacing and description of the computer system configuration are given in [2]. Automated systems'electrical, hydraulic and pneumatic circuitry; stand power distribution and control circuit diagrams; subsystem design and wiring diagrams; interconnecting cabling lists and parts lists are given in [3] along with a list of hardware vendor technical manuals for the components used. Design of components and assemblies with complete mechanical detail design and dimensioning is not presented. A glossary is included herein to define special terms. As requested by the sponsor, the computer system and software systems have been designed and configured for control of up to five stands. See Appendix $A$ and [1]. This report together with [2] and [3] are intended to serve as basic documents for duplication of this prototype system or for addition of hardware subsystems to control additional test stands.

Two important fuel control test parameters presently remain manual control parameters. These are power lever angle PLA, and compressor inlet temperature TT2. For a fully effective automated test system, these too should be automated. Automation of PLA should be straight forward, using for example, step motor control to position the input shaft on the fuel control. However, to speed up present testing, automation of TT2 would logically require simulating the output of the present fuel control temperature bulb system, a slow responding system requiring several minutes to settle at the desired setpoint value. This simulation would involve a change in test philosophy and test procedure for this control, along with special hardware designed to mate to the fuel control. Such an approach, however, is not new to the fuel control test industry, and should be investigated in this program.

* Certain commercial equipment or products are identified in this report in order to adequately specify the design. In no cases does such identification imply recommendation or endorsement by the National Bureau of Standards, nor does it imply that the material identified is necessarily the best available for the purpose.

** Numbers in brackets refer to references given at the end of this document. 
The role automated testing is likely to play in the fuel control calibration industry, along with brief discussions of present testing techniques and functions of fuel controls are given elsewhere, e.g. [4] and [5].

\section{HARDWARE SYSTEMS OVERVIEW}

Figure 1 shows the prototype hardware system connected to the fuel control and pertinent test stand systems. Test parameters which are under computer control are NC speed, PB pressure, and PT2 pressure, with additional systems for measurement of fuel control supply flow or total flow WT, metered fuel flow WF and various fuel control pressures and differential pressures. All parameters are read out as needed one at a time through a multiplexer system and preset counter, both under computer control. The blocks denoted PLA Input System and TT2 Input System are planned for future expansion and are not included in the present prototype system, as noted above. These are believed necessary for a fully effective automated test system.

The Operator Panel is equipped with a set of display lamps which indicate hardware and software systems status, a cathode ray tuhe (CRT) display system dedicated to fuel control test information including display of required values, operator inputs and test results, and a teletypewriter (TTY) for operator command inputs and hardcopy printout. Through the test stand relays, the computer can turn off the stand (stand emergency stop) and it can control the stand between conditions of drive stopped and stand systems unpressurized to stand systems fully pressurized and operative. The Pendant Station is used to manually control step motors in the various input systems.

Stand systems controlling the total flow schedule, boost pressure level, nozzle discharge pressure schedule, and fuel temperature remain unchanged. Indirect control of total flow WT is implemented through direct control of NC speed. PLA position and TT2 temperature (bath system) are currently manual parameters. Automation of TT2 would logically use a simulation approach positioning the fuel control temperature sense servo piston directly in place of the temperature (bulb) sensing system. Transfer between stand and automated systems is a manual operation.

The blocks at the top of Figure 1 show the computer system, defined to include the processor, a line printer, a paper tape reader and punch unit, a teletypewriter, a fixed head disc data storage unit, a clock module, and the device interfaces. This system is believed adequate for the end user who would be primarily concerned with changes in test specifications only, and who would be supplied with the software systems already programmed as a turn-key job.

Figure 2 shows the test stand console with the prototype Operator Panel located at the right, with the fuel control mounted on the stand drive pad at left center, and with the stand controls and instrumentation normally used by the operator located between these two items. 


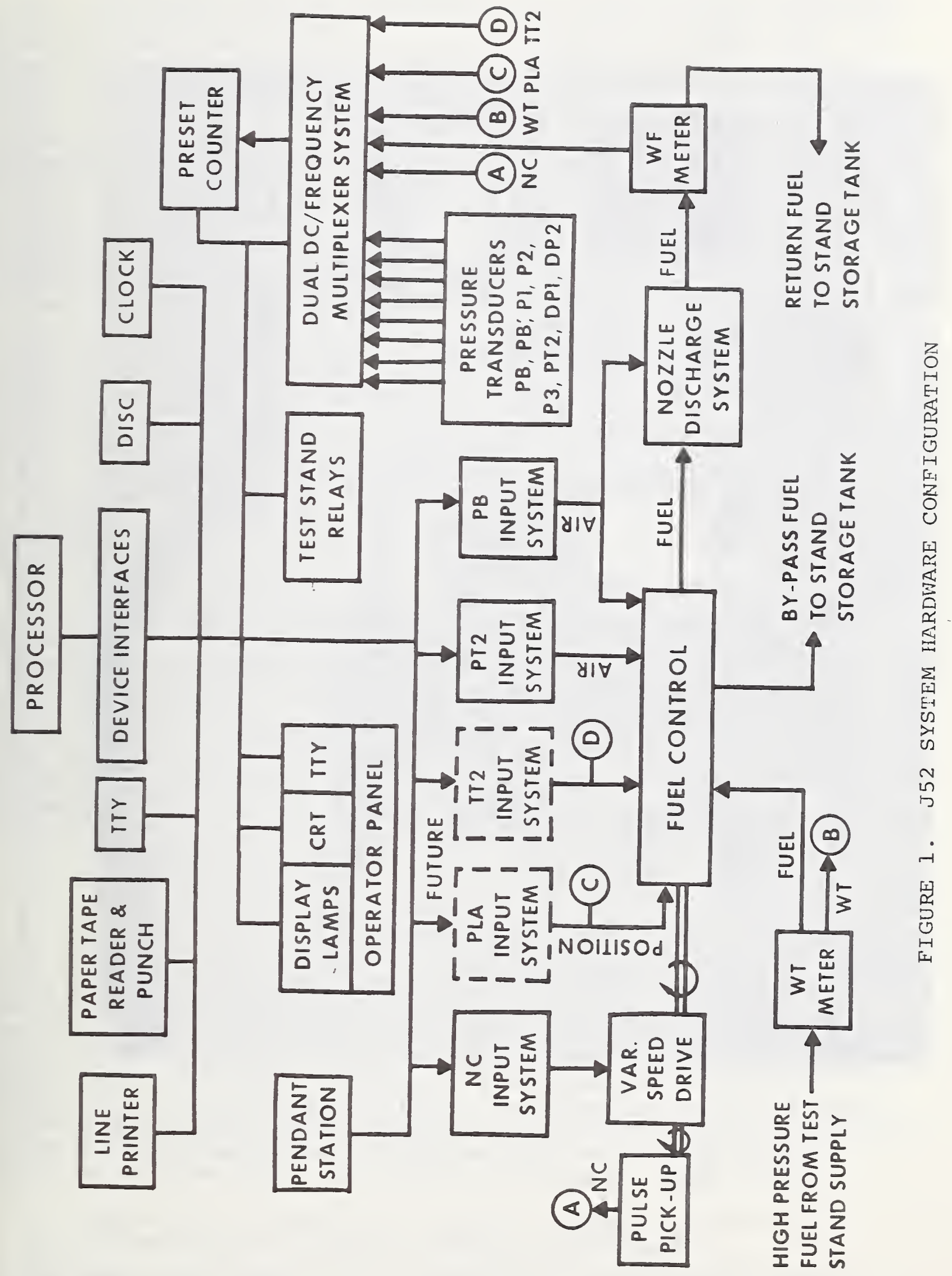




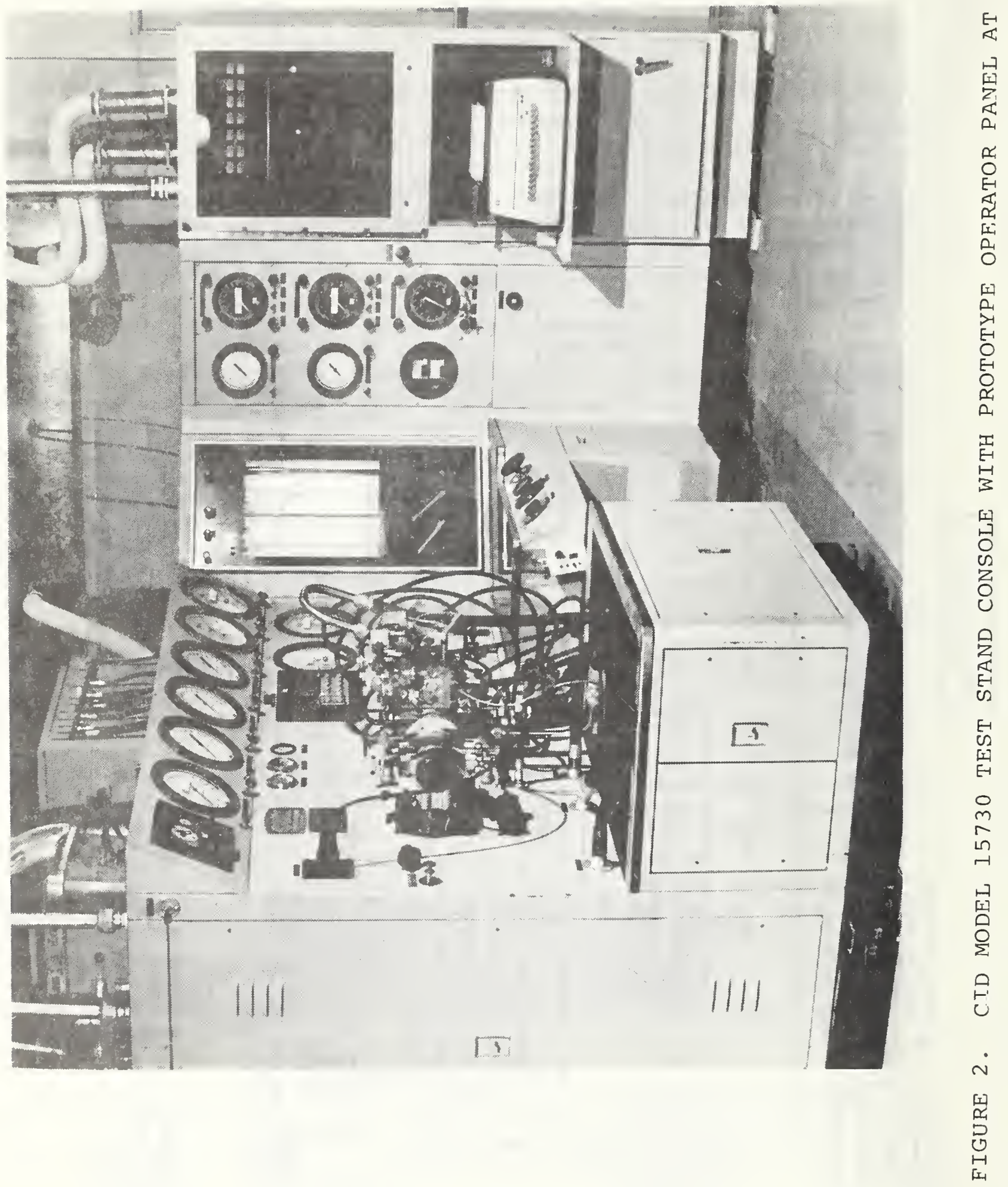


Figure 3 shows the computer system (from left to right) with the line printer; the teletypewriter; the processor with its display panel, the high speed paper tape reader/punch unit, and the disc all housed in CPU Cabinet 1; and the preset counter, $V / F$ converters, and a card file with interface boards all housed in CPU Cabinet 2.

The computer system consists of an Interdata Model 70 processor with $64 \mathrm{~K}$ bytes of core memory, a Pacific Micronetics Mode1 1-011-12B fixed head disc with 2.1 megabytes capacity, a Centronics Model 101A printer rated at 165 characters/sec, a Teletype Model KSR-37 TTY rated at 15 characters/sec, and an Interdata Model 7-413 high speed paper tape reader/punch unit rated to read 300 and punch 63 characters per second. Additional details for the computer system and test stand automation systems components are listed in Appendix B.

Except as noted below, the prototype system has been assembled using primarily off-the-shelf components. The device interfaces for the display lamps, the CRT, the TTY, the Test Stand Relays, the Dual Multiplexer and the Counter were designed and constructed at NBS, Division 650.01, and the signal conditioners for NC and WT signals in 213.06. The NC, PB and PT2 step motor interfaces were purchased from Technology Incorporated from designs used in the Navy TF30 fuel control test stand automation program, and the disc interface was purchased from Pacific Micronetics. The PB Input regulator is a modified design by Moore Products.

In addition to systems for control and measurement, and for operator interaction, suitable systems are needed to ensure safe operation for all hardware located at the test stand console area, a hazardous location where hydrocarbon vapors are always present, classified as Class 1, Group D, Division I in the National Electrical Code (NEC) [6]. All pressure and flow transducer equipment have been housed in totally-enclosed explosion proof boxes or purchased in such housings conforming to the NEC. A11 other equipment have been located in air purged enclosures in accordance with the requirements of the NEC. The purge air system added along with the automation hardware is discussed below.

\section{SYSTEMS DESIGN}

\subsection{NC Speed Control}

Figure 4 shows the NC speed input and readout systems, controlling NC speed under computer control in the range 50 to $4200 \mathrm{rpm}$, and to zero. For manual stand control, transfer switch item EA 537* is set in the MAN position, and the operator controls NC through stand console potentiometers E11 and E19**. For computer control, the transfer switch is set in the COMP position. NC control will be implemented through applications software. A supervisory software control loop has been used successfully in similar systems and is recommended here. This loop starts with reading current NC through the pulse pickup, followed by calculating the number of motor

* Item numbers with prefixes EA and A refer to components arded to the CID 15730 stand for the automated system, as listed in [2].

** Item numbers with prefix $E$ or no prefix refer to original stand system components as listed in [7]. 


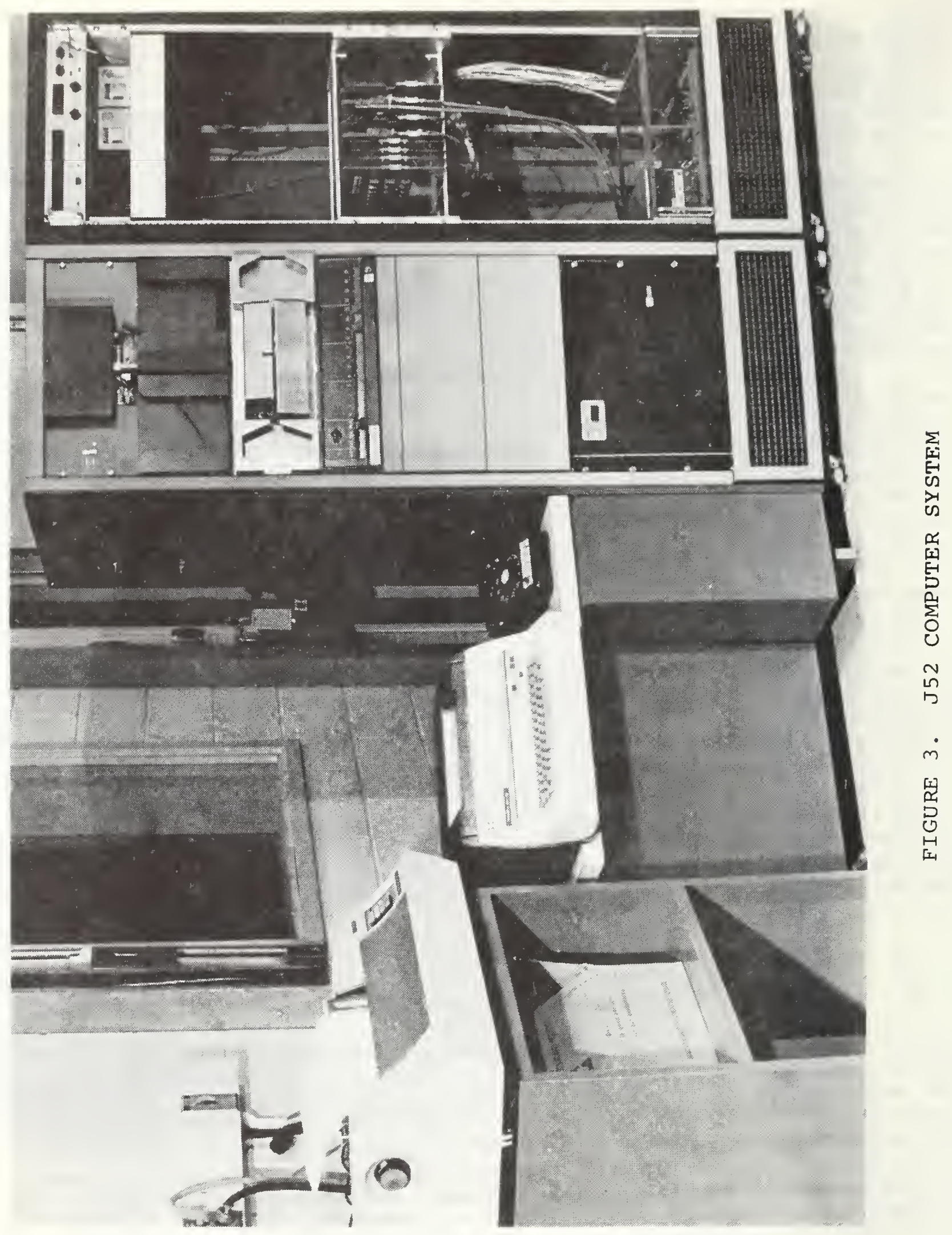


FUET

CONTROL

MAN/COMP
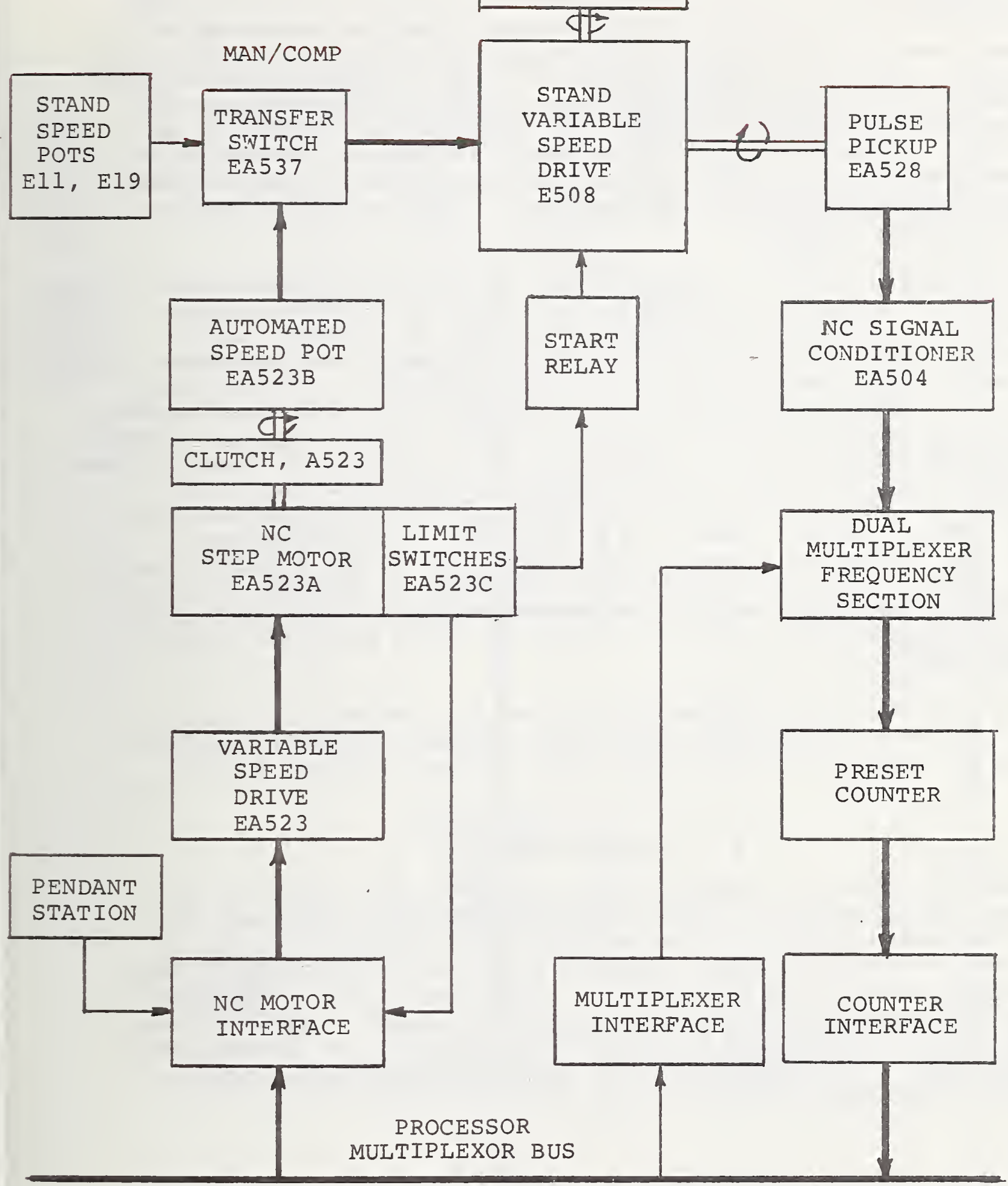

FIGURE 4. NC SPEED CONTROL 
steps necessary for setting WC to the next desired value. The motor would then be run in the appropriate direction about 90 percent of this amount, NC speed would be read again, and the process repeated several times. Thus, NC would be set in an iterative fashion to within a program-stored tolerance. Features of this system include counting step motor pulses in hardware, incorporation of high and low speed limit switches, and incorporation of a pendant station housing controls with which the operator can conveniently control the NC drive manually along with computer control. The low speed limit switch is set for zero speed and thus is used for start up and for control to zero speed.

Under computer control, the time necessary to control to a desired value to within a tolerance of $1 \mathrm{rpm}$ is estimated should not exceed about 14 seconds for a full scale speed excursion of $4200 \mathrm{rpm}$, allowing time for several NC reads and for the settling time of the drive after each motor run, and using a constant slew rate of about $800 \mathrm{rpm} / \mathrm{sec}$. This slew rate is set by a manual potentiometer (pot) adjustment on the step motor variable speed drive system, but is also limited by the individual test stand variable speed drive characteristics. Although the motor interfaces purchased included time delay circuitry, drive settling times are best implemented through software time delays for each drive as stored in a table of constants called TASK COMMON. This will result in a more flexible and usable automated production test system. Manual control of NC with the Pendant Station along with computer control will result in no speed "bumps". However, transfer between the stand speed pots and the automated speed pot should preferably be accomplished at zero speed to avoid possible large step speed inputs to the stand.

For details concerning programming of NC, see [1], Volume 1, Sections 5, $8.4,8.7$, and 9, Attachments A, B, C and H. Details concerning interface design are given in [2], and system circuit diagrams are given in [3].

\subsection{PB Pressure Control}

Automated PB inputs are generated in the range 5 to 300 psia* using the system shown in Figure 5. Under software control using an approach similar to $\mathrm{NC}$, a supervisory control loop would be used in which PB is varied by the step motor driven pressure regulator $P B$ REG, and read out through the system consisting of the $\mathrm{PB}$ transducer, a dedicated $\mathrm{DC}$ to frequency (V/F) converter, the Dual Multiplexer, and the preset counter. Control to a set point would be accomplished in a iterative fashion, running the step motor several times with $\mathrm{PB}$ reads in between until the desired value is set to within a programmed tolerance.

* To convert to SI units, multiply the pressure psia units by 6.895 to obtain corresponding pressure in kilopascals absolute. 
Valves $\wedge 501$ and $\mathrm{A502}$, located inside the stand console, transfer PB between the stand manual regulator REG 55 and the automated system. Stand regulator RE; 568 serves both systems as a pressure reducing regulator for air supply to the active $\mathrm{PB}$ regulator. $\mathrm{PB}$ pressure is always fed to stand pilot booster 580 which transmits $\mathrm{PB}$ to the back pressure valve in the nozzle discharge system. Since the exhaust pressure VAC EXH for the motor driven regulator PB REG varies with PB load, a low pressure regulated input VAC REF is needed to insure short term stability of the regulated output. This reference signal is nominally set in the range 1 to 3 psia. The pressure reducing regulator REG 568 limits forward leakage flow to the load, necessary to ensure $\mathrm{PB}$ control at the low end of the range. It senses $\mathrm{PB}$ and controls the pressure differential across PB REG (and REG 55) to about 25 psi.

Limit switches directly connected to the step motor shaft prevent over ranging at both high and low $\mathrm{PB}$ pressures, with status signals to the computer through the $\mathrm{PB}$ motor interface. When under computer control, the stand operator can vary and set $\mathrm{PB}$ manually with the Pendant Station.

Under computer control, it is estimated the time to set PB to within a programmed tolerance* through an excursion of 200 psi will not exceed about 17 seconds. Smaller PB excursions will take less time; for example, an excursion of $20 \mathrm{psi}$ is estimated would not require more than 6 seconds. The avallable slew rate for setting $P B$ is about $20 \mathrm{psi} / \mathrm{sec}$. The control times allow for several reads of PB and for PB system settling time or lag. The maximum lag for the prototype system is about 1 second which occurs at low $\mathrm{PB}$ in the range 5 to $10 \mathrm{psia}$. This $\mathrm{lag}$ is due to the time it takes for air in the PB load circuit between PB REG and the fuel control to exhaust to VAC EXH, limited by sonic flow within parts of the regulator itself. This regulator, Moore Model 40AE450(M66), was purchased with increased exhaust flow capacity as modified by Moore Products. A dedicated vacuum pump, 8 CFM capacity, is used with the PB system to prevent interaction with the PT2 system. This pump has been added to the stand console system.

\section{Caution}

To avoid possible high $\mathrm{PB}$ step inputs to the fuel control, transfer with valves $\mathrm{A} 501$ and $\mathrm{A} 502$ between the stand $\mathrm{PB}$ regulator 55 and the automated system should occur with the high pressure air supply turned off.

Detailed information needed for programming PB control is included in [1]; see Volume 1, Sections 5, 8.7, and 9, Attachments A, B, C and I. Details concerning interface design are given in [2], and system circuit diagrams are given in [3].

* As given in [1], the tolerances are 0.05 psi for $\mathrm{PB}<100$ psia, and 0.10 for $\mathrm{PB} \geq 100$ psia. 


\section{3 PT2 Pressure Control}

Automated PT2 inputs in the range 1 to 30 psia are generated with the system shown in Figure 6 with the motorized regulator PT2 REG. This system is functionally similiar to that for $\mathrm{PB}$ control including use of a supervisory control approach. Minor differences include control to closer tolerances (to $0.01 \mathrm{psi}$ ), incorporation of a dedicated pressure reducing regulator REG $A 538$ rather than sharing a reducing regulator with the stand system, and no requirement for a vacuum reference signal for PT2 REG. Again, a dedicated vacuum pump, 3.5 CFM capacity, for VAC EXH is used, isolating the PT2 and PB systems. This is the pump originally installed in the stand console.

Under computer control, it is estimated no more than about 16 seconds maximum will be required to set PT2 through an excursion of 20 psi. This uses a slew rate of about $2.9 \mathrm{psi} / \mathrm{sec}$, as set by manual pot adjustment on the PT2 variable speed drive system, and allows for similar PT2 system lags or settling times (about 1.5 seconds in the range 1 to 2 psia). Smaller PT2 excursions will require less time, for example an excursion of 2 psi should not require more than about 6 seconds for control to the set point.

Detailed information needed for programming PT2 control is included in [1]; see Volume 1, Section 5, 8.7, and 9, Attachments A, B, C and I. Details concerning interface design are given in [2], and system circuit diagram are given in [3].

\subsection{WF and WT Measuring Systems}

Discharge flow from the fuel control is measured by the WF Turbine Meter system as shown on Figure 7. This system consists of a turbine meter WF METER, a flow straightener section upstream, a section of straight tubing downstream, and the WF signal conditioner whose output is fed to the preset counter through the Dual Multiplexer. Measurements of WF can be made in the range 300 to $11,000 \mathrm{lb} / \mathrm{hr} *$ to an uncertainty not exceeding, 0.5 percent of rate. The approach is to determine meter frequency by measuring the period required for a predetermined number of pulses. In this way, adequate resolution is obtained in 0.5 second nominal, an interval sufficient for a steady sample of the (fluctuating) flow, and much less than the time it would take to measure frequency directly at low flow rates. The necessary predetermined number of pulses will vary with flow rate and is first determined by a preliminary, or sample perfod count taking 0.2 second nominal. Thus, an accurate measurement of WF will require about 0.7 second.

* To convert to SI units, multiply the flow rate in $1 \mathrm{~b} / \mathrm{hr}$ by 0.4536 to obtain corresponding $\mathrm{kg} / \mathrm{hr}$. 


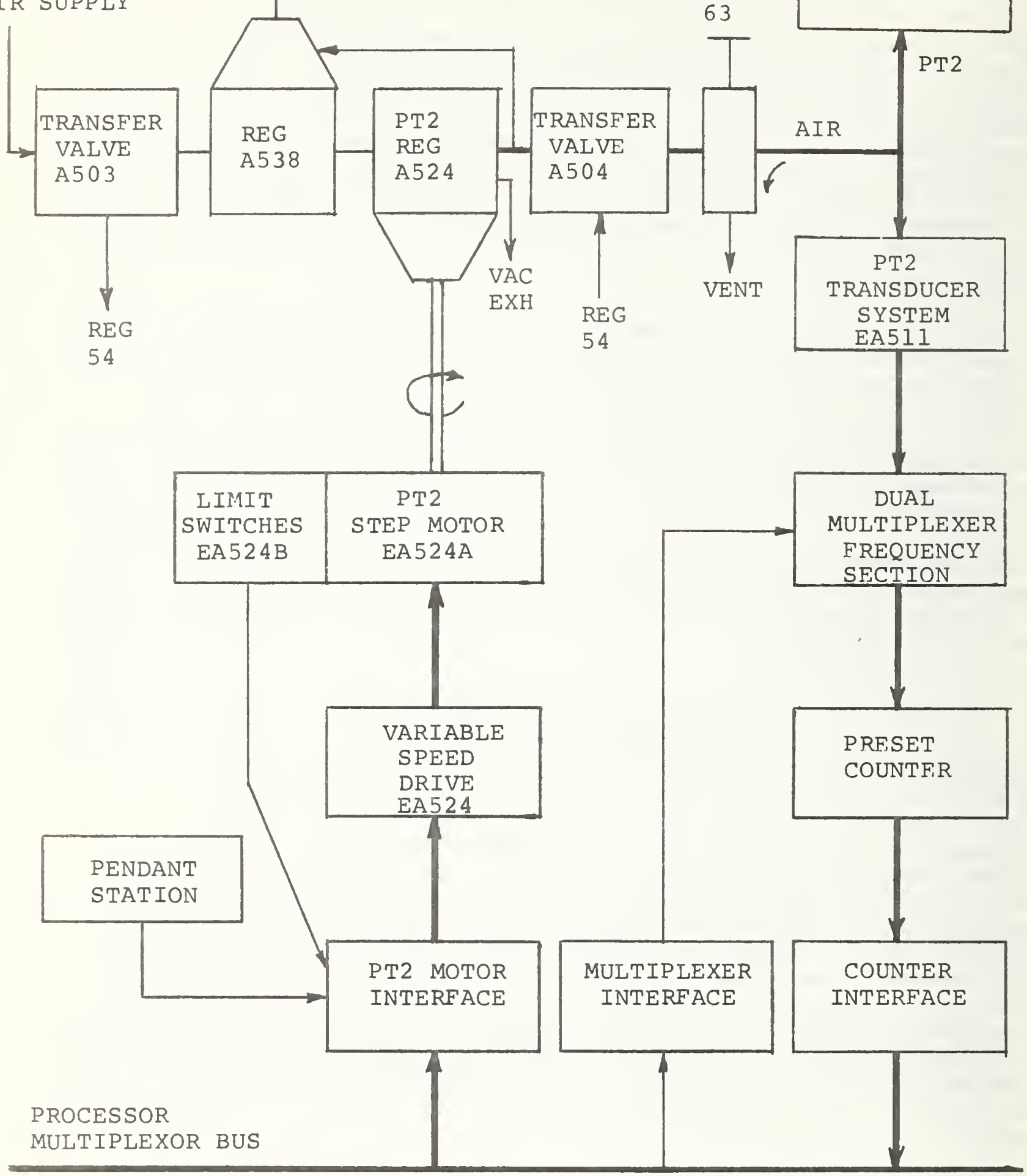

FIGURE 6. PT2 PRESSURE CONTROL 


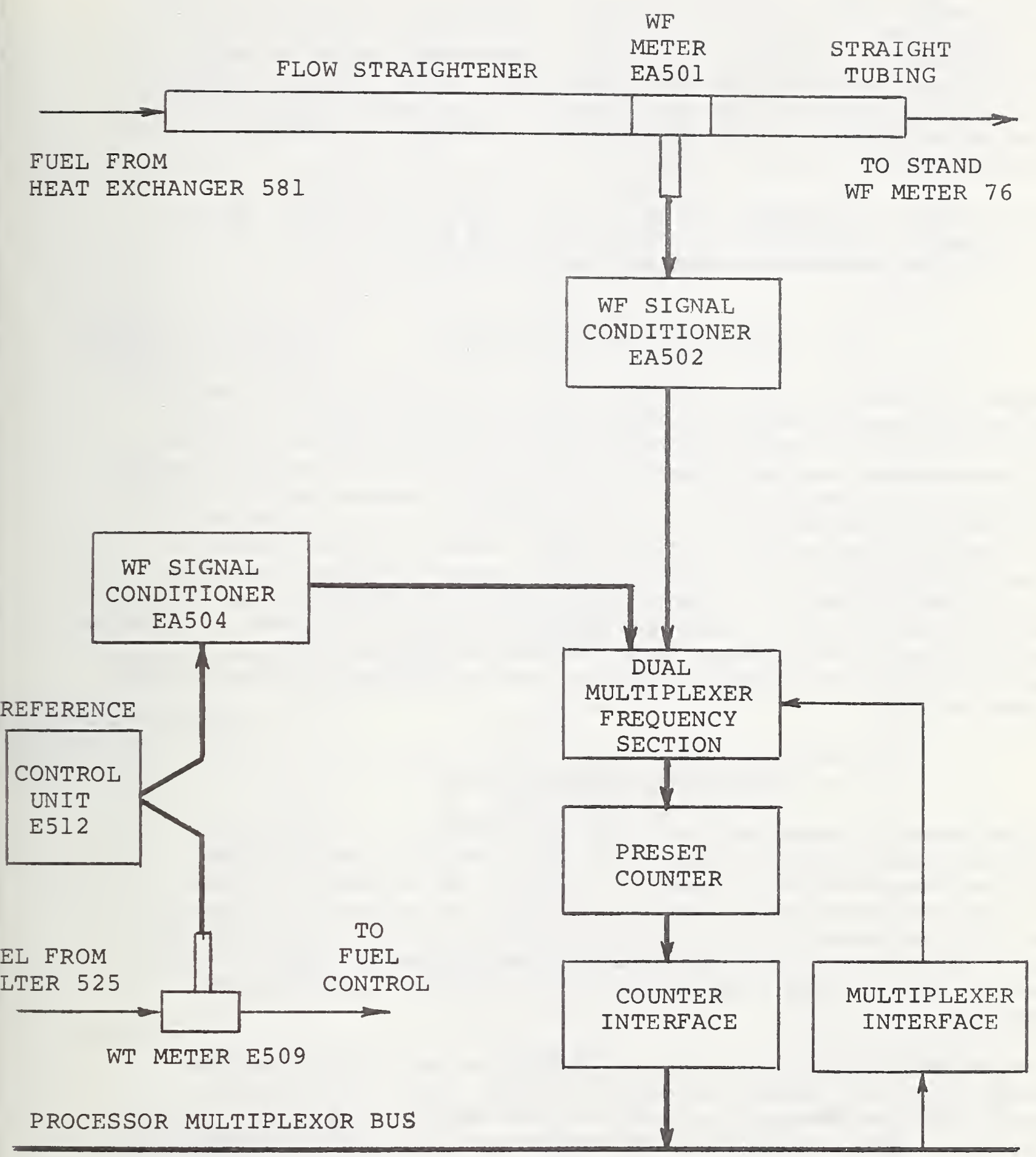

FIGURE 7. WF AND WT MEASURING SYSTEMS 
Total flow WT, the inlet supply flow rate to the fuel control, is ubtaind using the turbine meter item E509 originally installed in the stand. The meter output signal is connected to the Dual Multiplexer through an added signal conditioner. In this case, a direct pulse count for 0.5 second gives sufficient resolution for this measurement. Stand item F512 Control Unit is shown for reference. WT measurements in the range 1000 to 15,000 $\mathrm{lb} / \mathrm{hr}$ to an uncertainty not exceeding 1 percent of rate are made with this system.

Details for use of the WF and WT meters under software control are given in [1], Volume 1, Section 9, Attachments B, F (for WF) and G (for WT). Circuit diagrams for these systems are included in [3].

\subsection{Pressure Measurement Systems}

Measurements of burner pressure limiter pressure PC, differential pressures D1 and D2, and gauge pressures P1, P2, and P3 are made through the system as shown on Figure 8. The PC transducer is dedicated to the burner pressure limiter measurement, but the other transducer systems are shared with various test parameters as needed.* All of these transducer systems employ a DC voltage output and share V/F Converter 1 as fed through the Dual Multiplexer. These transducers are rated at 0.15 percent of range including linearity, hysteresis and repeatability. Additional information including ranges are given in Appendix $B$ herein. Other signals, varlable frequency pulse rates for NC, PB, PT2, WF, WT and spares are shown for reference purposes. Procedures for making pressure measurements under computer control are given in [1], Volume 1, Section 9, Attachments B and I. Circuit diagrams for these systems are given in [3].

\subsection{Operator/Machine Interaction}

The stand operator communicates with the automated test system through the Operator Control/Display Panel (Op Panel) located at the right hand side of the stand console as shown on Figure 9, and through the Pendant station for step motor manual control. The op Panel contains a teletypewriter (TTY) for command input, and hardcopy printout at 15 characters per second; a Cathode Ray Tube Display (CRT) system capable of display of 640 characters; and a Display Lamp Panel having 36 displays used for short messages.

The CRT system is used for the display of fuel control test information including test point number, automated test mode, input and observed parameter data, and message data such as stand operator action or instructions. Utilization of the CRT during test point processing is discussed in detail in [1], Volume 1, Section 4.10. Th1s system is composed of a 23-inch size video monitor Electrohome Model EVM-23 and a character generator Digi-Log Model 209. Characters are approximately 0.5 inch high

* Symbols D1, D2, P1, P2 and P3 designate automated system hardware only, and are not fuel control test parameter designations. See [1], Volume I, Section 9, Attachment A which 1 ists both test parameters and automated system hardware. 


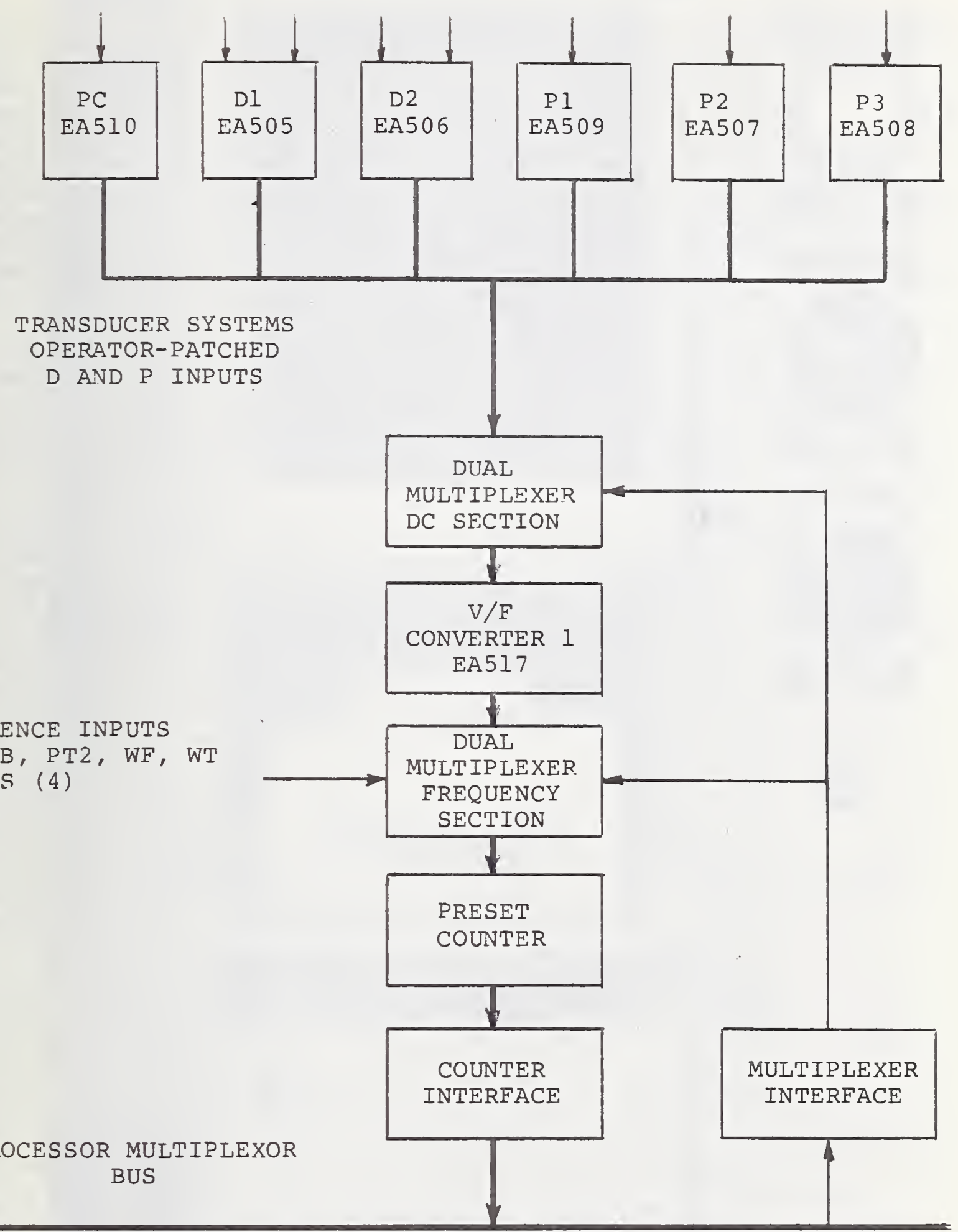

REFERENCE INPUTS

$\mathrm{NC}, \mathrm{PB}, \mathrm{PT} 2, \mathrm{WF}, \mathrm{WT}$ SPARES (4)

FIGURE 8. PRESSURE MEASURING SYSTEMS 


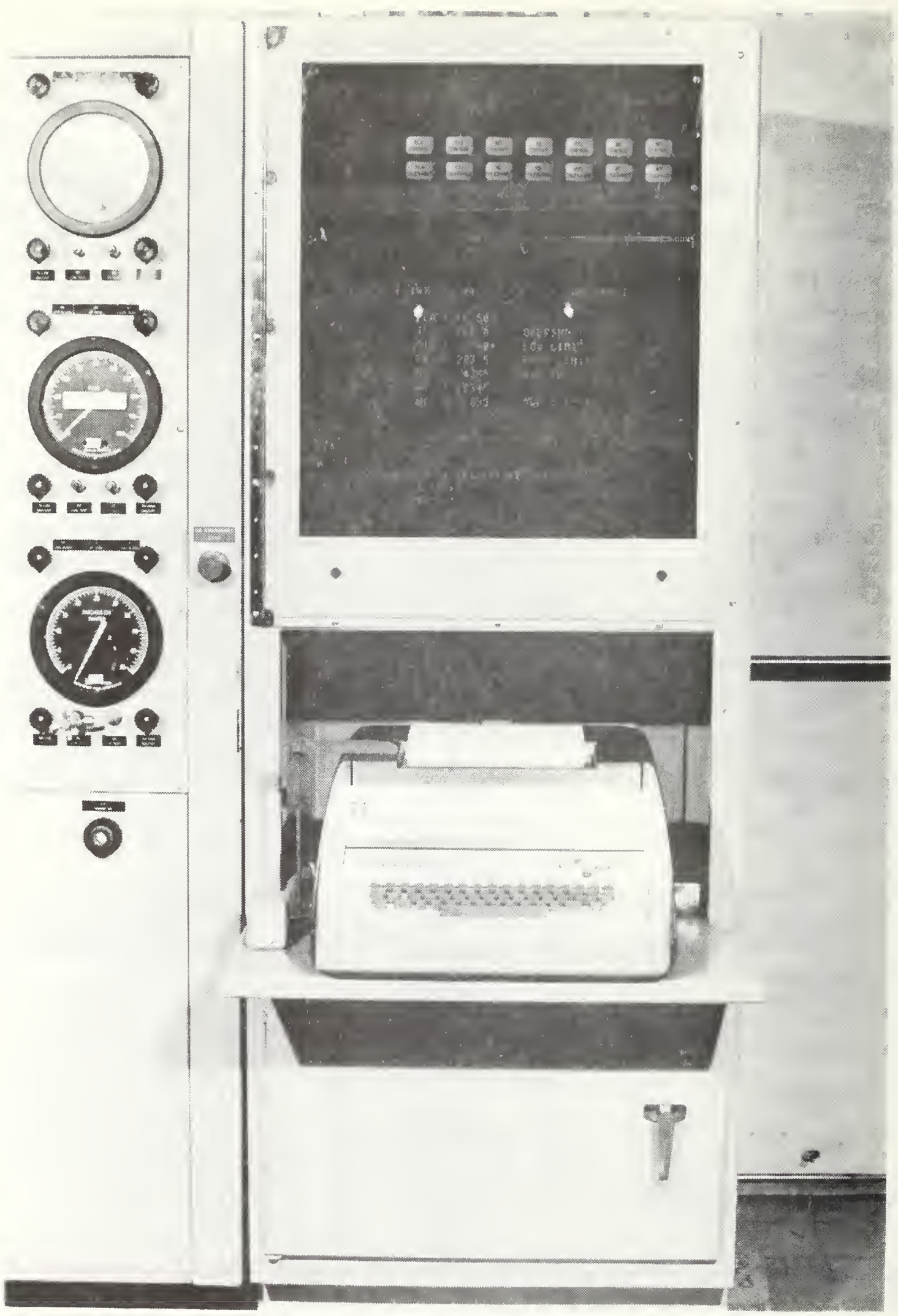

FIGURE 9. OPERATOR CONTROL/DISPLAY PANEL 
and each is formed by a $5 \times 7$ dot matrix. Sixteen 1 ines of 40 characters each can be displayed at a maximum of 872 characters/second ( 9600 baud data rate, 11 bit code). With nominal software overhead time, about 1 second will be required to fill the screen. The character height affords easy viewing for the operator at any position in his work area. Controls for adjustment of screen quality are available behind the lower access door without power shutdown of the Op Panel or program interruption. Removal of the front or rear panel does require power shut dorm, as interlocked through a purge air pressure switch as discussed below. See Figure 10 for a view of the CRT and Display Lamp Panel with the front panel removed.

The TTY (Teletype Model KSR-37) is positioned with the keyboard 14 inches forward of the CRT so that the printed page is easily viewed and to allow opening of the TTY case. The lever system shown on the left of the TTY activates a mechanical switch which shuts off TTY power when the case is opened. The TTY electrical service unit (ESU) is located in the lower chamber of the Panel.

The Display Lamp Panel (Technology Inc. Model 112) is used to output status information for automated hardware systems including indicators for purge air and equipment power; error conditions for the processor, for hardware I/O, and for illegal stand operator commands; and for status of the parameters under control, namely NC, PB, PT2, WF, WT, and future PLA and TT2. Indicated status includes step motor high and low limits, motor control (running) status including overshoot indication, and parameter in-tolerance and out-oftolerance status at the set point. Use is made of red, green and yellow lamps, and on/off and flashing modes. Figure 10 shows the status messages for this display panel. Detailed specifications on use of this display panel are given in [1], Volume 1, Section 4.11. All lamps except those indicating purge air and power status are under program control. Further, all control and tolerance lamps can be disabled as a group with an added internal switch in the upper chamber of the Op Panel, an NBS modification. Thus with this flexibility, production experience and operator preference can be deciding factors whether or not these two sets of lamps are in use continuously.

Figure 11 shows the Pendant Station for step motor manual control. With the stand under computer control with the ACJET system, the stand operator can, at any time, conveniently control each step motor individually except during those periods when the motor is actually being run under computer control. Changing between manual and computer control is bumpless. The operator selects a parameter (NC, PB or PT2) by a knob switch; the direction (forward or reverse) through a rocker switch; and then one of three motor slew speeds or jogs the motor, all through a set of four momentary push buttons. Slew speeds include FAST, which enables a full scale traverse ranging from 8 to 10 seconds depending upon parameter selected, a MEDIUM slew speed ranging from 20 to 30 seconds for full scale, and SLOW, which normally enables satisfactory control to a setpoint. In addition, the JOG position enables closer control with discrete numbers of motor pulses output for each switch actuation. Although not shown on the controls, possible expansion to include operation of motors for PLA and TT2 control has been included in the design. 


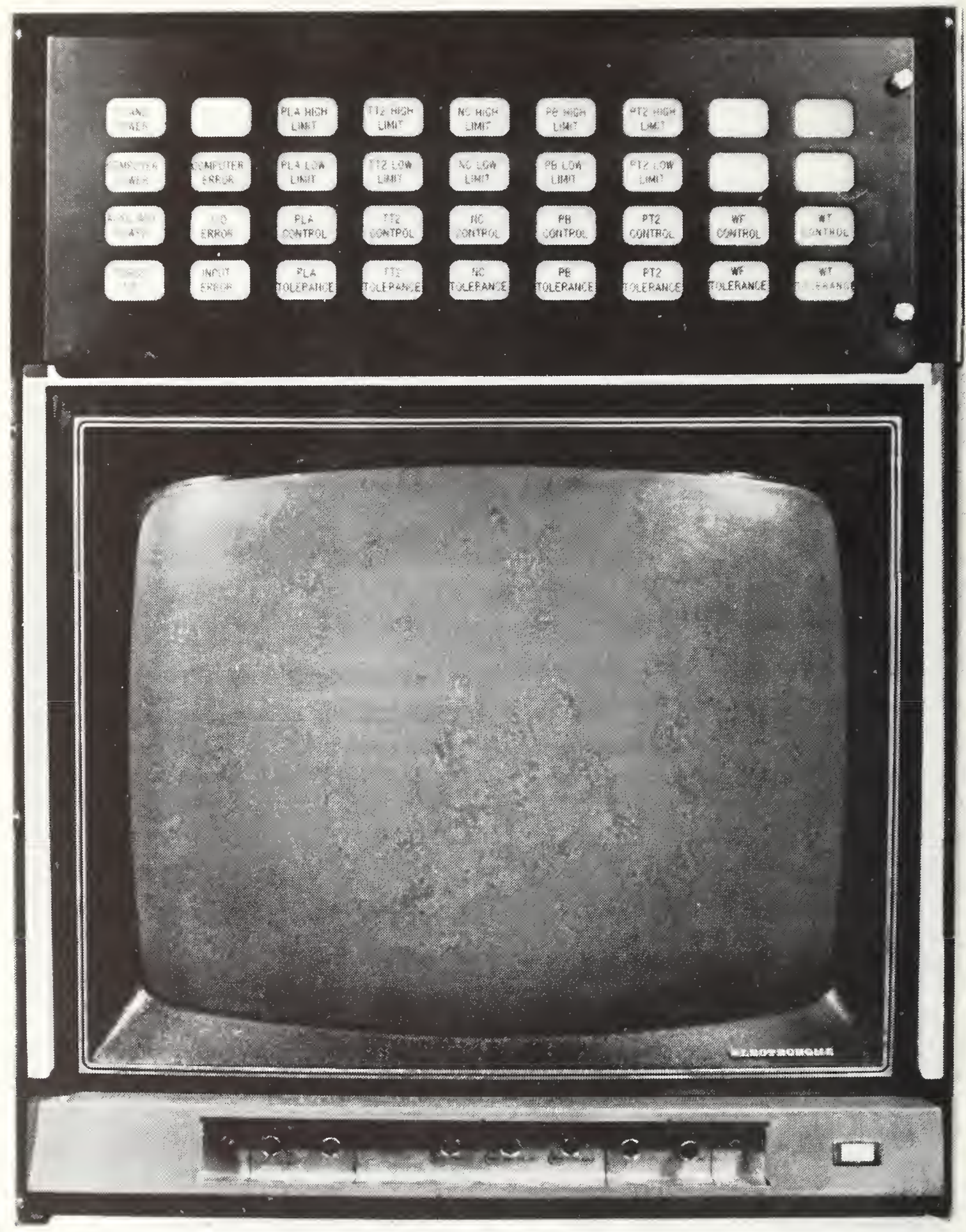

FIGURE 10. CRT AND LAMP DISPLAY PANEL 


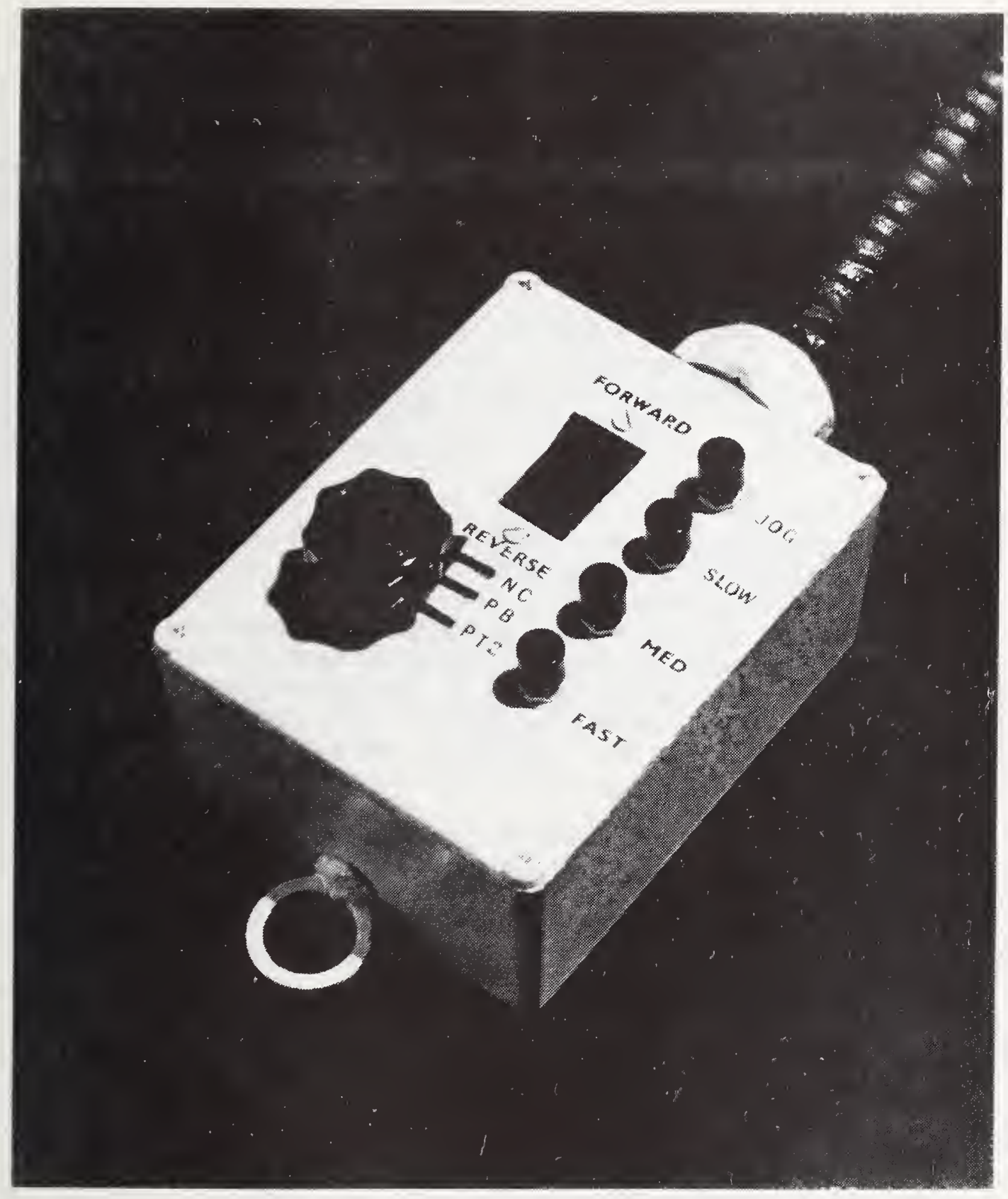

FIGURF 11. PENDANT STATION FOR STEP MOTOR MANUAL CONTROL 
This station is mounted on a flexible hose near the center of the stand console and allows the operator to control these motors from positions within a reasonably large part of his normal work area. This hose houses the necessary electrical conductors and also conducts purge air to the Pendant Station.

\subsection{Test Stand Control and Power Flow}

A set of computer-controlled relays are used to control the following stand functions or systems: stand emergency stop, fuel boost pump power, fuel high pressure pump power, vacuum pumps power, and stand varlable speed drive DC controller power. Also, operation of the fuel control manual/normal transfer system is similarly under computer control.

Figure 12 depicts power flow for these systems. For manual control of the test stand, computer control of stand emergency stop through relay Kl and the purge air interlock through pressure switch PSI are both made inactive by manual switch F.A537 located in the stand electrical control cabinet, and with no computer control relays $\mathrm{Kn}$ energized, all stand systems are operated normally through stand controls. Pressure switch PS1, which senses the purge air supply pressure, is the primary interlock between the test stand and the automated systems when under computer control since it interlocks with stand relay CRI controlling power to the stand control circuit.

The computer controlled relays are connected to duplicate the operation of the stand momentary push button switches and when under computer control, each relay is actuated momentarily upon receipt of a command byte from the computer. Thus, stand systems manual stop and start push buttons are always active and the operator is never "locked out".

Under computer control, power to the stand variable speed drive DC controller is controlled through the low limit switch on the NC step motor. Thus, start up must occur from zero speed, duplicating manual stand operation. To stop the drive alone, NC motor must be driven to the low limit position under computer control, or the operator must actuate the Varlable Speed Drive stop button.

Two pairs of relays, K8 through K11, control operation of the fuel control manual/normal transfer system. These are latching type relays duplicating operation of stand toggle switches. Relays $\mathrm{KlO}$ and $\mathrm{K} 11$ control power to the AC and DC power supplies for this system, and $\mathrm{K} 8$ and $\mathrm{K} 9$ control the transfer. The latter pair are interlocked to override stand switch E2 position. Thus, computer control overrides manual control, except the computer cannot de-energize the power supplies should stand toggle switches F2 or E9 be closed.

\section{Caution}

The operator should keep stand switches E2 and E9 in the "off" position except when needed manually.

Computer software will keep these relays unenergized except when fuel control manual/normal transfer is needed, 


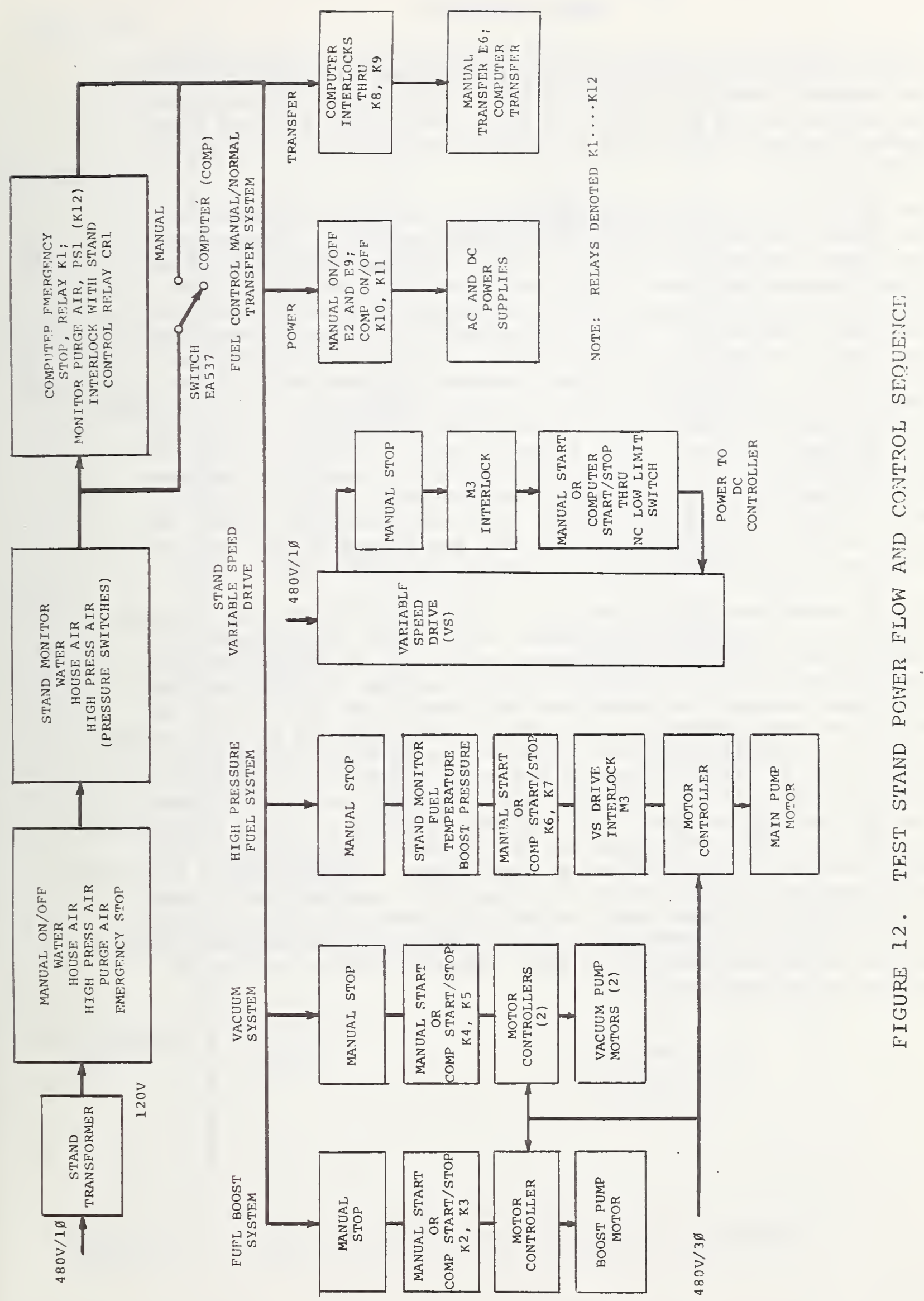


All electrical or electronic equipment added to the test stand console have been installed in accordance with the National Electric Code, i.e. either housed in totally enclosed explosion proof boxes or located in purged air enclosures as required in [6]. The pressure and flow transducer equipment have all been located in explosion proof boxes or purchased in such housings.

Figure 13 shows the flow circuit through the air purged enclosures and the physical location of all safety interlock switches. A centrifugal blower, rated $865 \mathrm{CFM}$ at 6 inches of water, supplies purge air from an adjacent nonhazardous area. Three temperature switches (TS) and four pressure switches (PS) sense enclosure air temperature and pressure at the locations indicated. This system operates at pressures considerably higher than pressures corresponding to 0.1 inch of water column, the required minimum, principally because pressure switches which operate satisfactorily at 0.1 inch are generally less available and more expensive. To avoid excessive pressures in the upper and lower chambers of the op Panel, pressure is sensed in the purge air supply line with restrictions as shown adjusted so that opening either chamber actuates its pressure switch. Purge air for the TTY flows from the lower chamber of the Op Panel up through a cable slot passage via a special adaptor box at the rear of the TTY. Mechanical switches (MS) are located at the lower chamber door and on the TTY cover, both of which can be opened without tools.

Figure 14 summarizes 120V AC power flow to the automated systems hardware as controlled by the safety interlocks. All control occurs through $12 \mathrm{~V}$ DC relays, two of which are the time delays shown. As noted previously, pressure switch PS1 is the primary interlock between the test stand and the automated systems. It interlocks with stand relay CRI controlling power to the stand control circuit and when under computer control, purge air must be "on" before the test stand and the automated hardware in the hazardous area at the stand console can be energized. To allow sufficient time for purging prior to power up, time delays are used; one dedicated to the Op Panel TTY, so that opening up the TTY cover for paper adjustment for example will only power down the TTY, and one dedicated to the CRT/ Displays and the PB/PT2 Motor Box as shown. When a "Fault" occurs (enclosure open or temperature high), power is automatically restored only through the appropriate time delay once the Fault is cleared (trouble corrected). All other automated hardware are powered directly through Auxiliary Racks 1 and 2 located in a nonhazardous area. Detailed power distribution circuitry is included in [3]. 


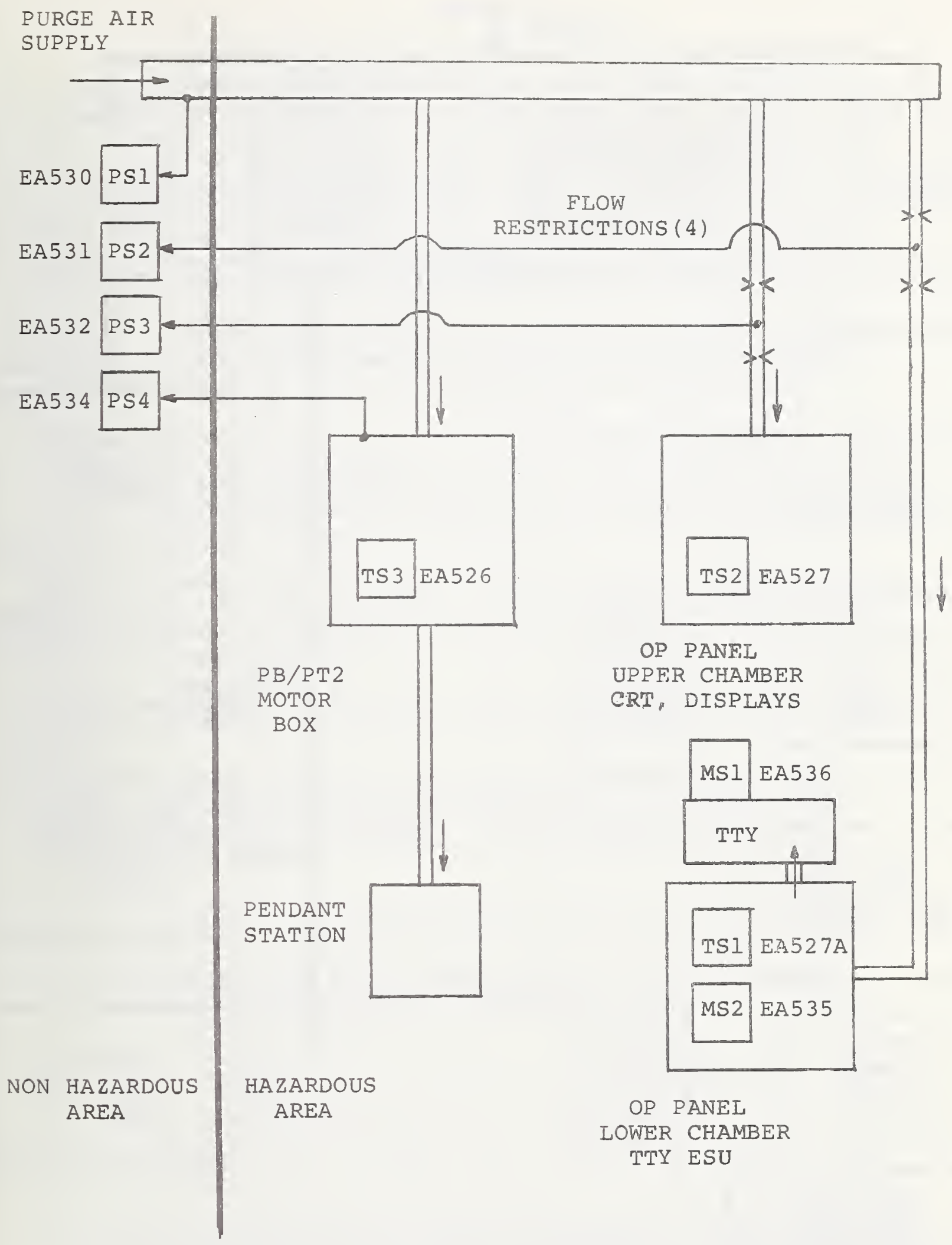

FIGURE 13. PURGE AIR CIRCUIT AND INTERLOCK LOCATIONS 


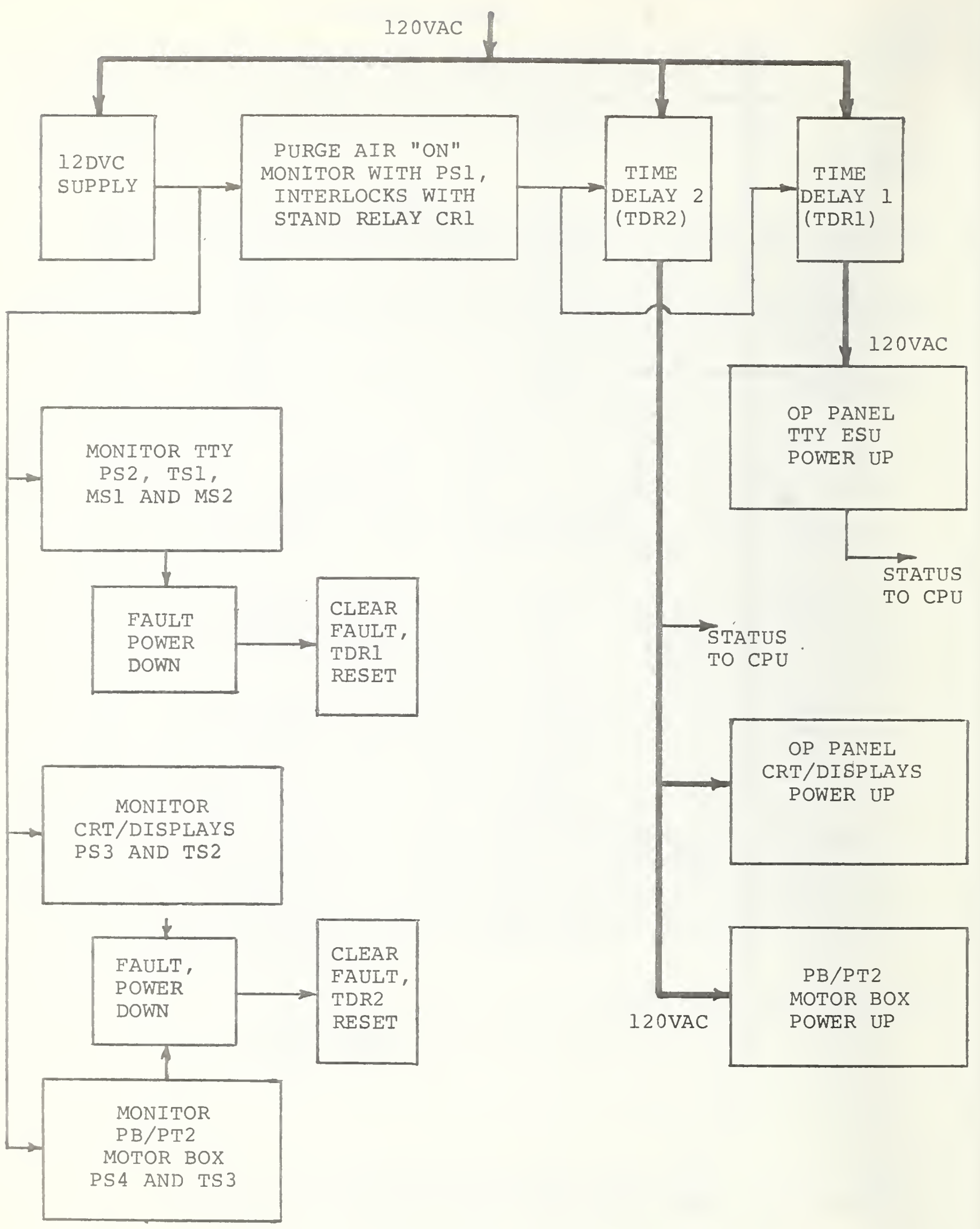

FIGURE 14. POWER FLOW TO AUTOMATED SYSTEMS, SAFFTY INTFRLOCKS CONTROL 
1. ACJET, Accessory Calibration for Jet Engine Tuneup, Volumes 1 through 10, William C. Haight and Helen Wood'Hawes, National Bureau of Standards, Washington, D.C. [A software system submitted to Naval Air Systems Command under the J52 Engine Fuel Control Test Stand Automation Program, May 21, 1975]

2. A Prototype Automated Test System for J52 Engine Fuel Controls; Part 2, Computer System Configuration and Interfacing, Alfred L. Koenig, Nationa1 Bureau of Standards*

3. A Prototype Automated Test System for J52 Fngine Fuel Controls; Part 3, System Design and Installation, David W. Baker, Alfred L. Koenig and Victor Brame, Jr., National Bureau of Standards*

4. An Automated Prototype Test System for Aircraft Engine Fuel Controls, Design and Operating Experience, David W. Baker and Alfred L. Koenig, National Bureau of Standards, Washington, D.C. 20234, Proceedings for 13th Annual Technical Symposium, Washington D.C. Chapter Association for Computing Machinery, June 20, 1974

5. An Automated Tuneup, Calibration of Jet Engine Fuel Controls, William C. Haight and Helen Wood Hawes, Automatic Support Systems Symposium for Advanced Maintainability, IEEE, Oct. 30-Nov. 1, 1974. See also [1], Volume 1, Section 0

6. National Electrical Code, 1971, National Fire Protection Association, NFPA No. 70

7. Operation and Service Instructions with Parts Catalog for Model CID 15730 Stand Assembly, Fuel Control Test, Type 84654, Serial Nos. 130016-1, -2, 8 December 1971, DoD Contract No. N00-383-71C-5576, Cox Instrument Division of Lynch Corporation, Detroit, Michigan

8. User's Manual, Interdata Incorporated, publication No. 29-261R03

9. Real Time Operating System (RTOS) Reference Manual, Interdata Incorporated, publication No. 29-240R07

* For additional information, contact the author(s). Work on this document, in preparation at the publication of NBSIR-76-1051, has been suspended while changes in this automation program are under consideration by the sponsor. 
The computer system has been designed and configured to accommodate up to 5 automated test stands as follows. With reference to Figure 3, CPU Cabinet 1 has slots available for 5 CRT Display interfaces and 5 Op Panel TTY interfaces with sufficient power supply capacity available to handle the full complement. CPU Cabinet 2 has sufficient room to accommodate card files and power supplies for up to 5 stands. If the number of stands automated does not exceed three, Cabinet 2 may also house the electronic counters and frequency converter equipment, but for four or more stands a third CPU cabinet will be needed for these items.

The computer multiplexor bus has been regenerated with bus buffers sufficient to drive the computer peripherals and one set of stand automation interfaces. When additional stands are automated, one more buffer must be added in CPU Cabinet 1; an expansion chassis slot has been reserved for this. In Cabinet 2 a card file, complete with bus buffer and interfaces, is required for each additional stand automated. Also, additional power supplies will be needed, one for each card file.

Each additional CID 15730 stand automated will require a set of stand automation devices as 1isted in Appendix B, item III, along with necessary housing components including a PB/PT2 Motor Box, a PB/PT2 Transducer Box, a Resistor Box, an Op Panel enclosure and one each of Auxiliary Racks 1 and 2 (see Figure 15). Other equipment needed include an additional vacuum pump for the $\mathrm{PB}$ system or equivalent capacity if more than one stand served by one pump is desired, and a set of transfer valves for the PB and PT2 systems are needed. A detailed parts list comprising a stand automation device set is contained in [3]. 


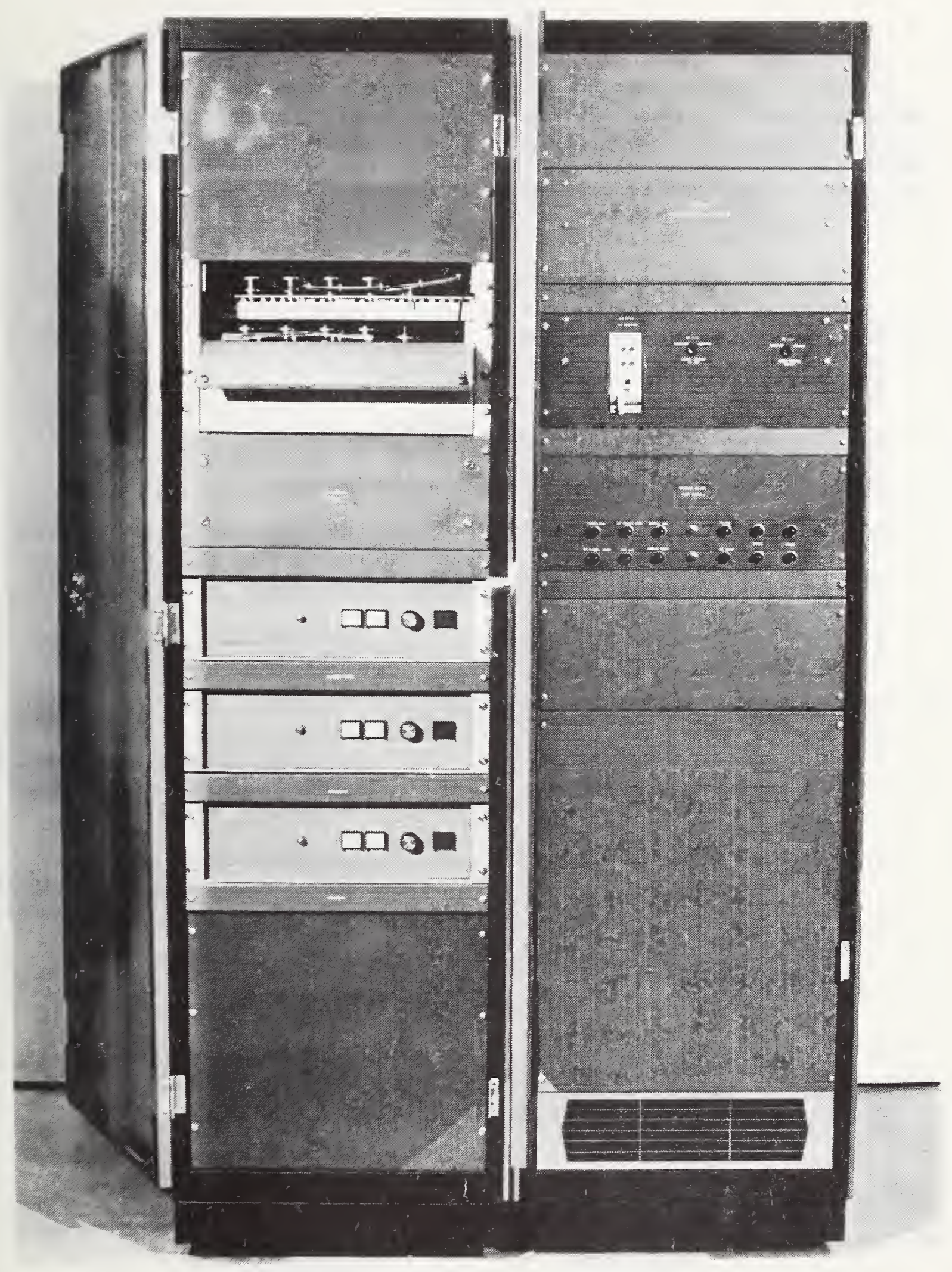

FIGURE 15. J52 SYSTEM AUXILIARY RACKS 1 AND 2 
Hardware components listed include the computer system and components for one test stand. Each additional test stand requires an additional set of stand automation devices, item III. Where applicable, device interface supplier and nodel number are shown in parenthesis.

Manufacturer and Mode1

I. A Central Processor Unit (CPU)

Interdata 70

with $64 \mathrm{k}$ bytes of core memory

with options:

1. Power fail with auto restart

M70-100

2. Automatic Memory Protect

M70-101

3. Selector Channel

M70-103

4. Universal Clock Module

M48-000

5. Cabinets (two)

M49-004

M49-005

II. Peripherals:

1. Disc memory, 2.1 M bytes

Pacific Micronetics 1-011-128

(Progress Electronics Co. of Oregon, Is 4-10)

2. Console teletypewriter, 15 char/sec

Teletype KSR-37

(NBS Design, 650.01, 2/15/73)

3. High-speed paper tape reader, $300 \mathrm{char} / \mathrm{sec}$, and High-speed

Interdata 7-413 paper tape punch, $63 \mathrm{char} / \mathrm{sec}$, (includes interface) unit

4. Line printer, $165 \mathrm{char} / \mathrm{sec}$

Centronics 101A

(Interdata M46-202)

III. Stand Automation Devices:

1. Operator teletypewriter, $15 \mathrm{char} / \mathrm{sec}$

Teletype KSR-37

(NBS Design, 650.01, 2/15/73) 
2. Operator CRT display (video monitor), and character generator, 9600 baud

3. Display lamp pane1, 36 status message display units

4. Reed Relay dual multiplexer, 10 channels for DC inputs

10 channels for pulse rate inputs

5. Preset counter, 5 digits

6. DC Voltage to frequency converters (2 each)

7. Test stand control relay unit, 12 relays under computer control

8. Stepping motors with variable speed drives, for NC speed, and $\mathrm{PB}$ and $\mathrm{PT} 2$ pressure input systems

9. Potentiometer, 2000 ohms for NC input system

10. Pressure regulators for $\mathrm{PB}$ and $\mathrm{PT} 2$ input systems

11. Transducers for Data Acquisition

Parameter

Instrument

WF

Turbine meter; 0.5 to $65 \mathrm{gpm}$; signal conditioner and flow straightener

WT Turbine meter, 5.0 to $50 \mathrm{gpm}$; and signal conditioner

NC Pulse pick up; and signal conditioner

$\mathrm{PB}$
Electrohome EVM-23, Digi-Log 209

(NBS Design, 650.01, 5/3/73)

Technology Inc. 112

(NBS Design, 650.01, 10/21/74)

NBS Design, 650.01, 10/31/73

(includes interface)

Eldorado 1411

(NBS Design, 650.01, 11/9/73)

Anadex DF-100

NBS Design, 213.06, 7/15/74

(NBS Design, 650.01, 9/13/74)

USM Responsyn HDM-150-1600-8

1 each for NC and PT2

HDM-1600-800-4, 1 for $\mathrm{PB}$

(Technology Inc. 71E45572)

Beckman Helipot 7603

Moore Products 40AF,450(M66)

1 for $P B$

Models 44-50 and 40AE50

1 each for PT2

Manufacturer and Model

Cox Instrument ANC-16;

104-026 and 60043-16

Cox Instrument AN-16-2;

NBS Design, 213.06, 2/26/74

Electro 3045A;

NBS Design, 213.06, 2/26/74

Bell and Howell

4-332-0168

$1-169$ 
Parameter

Instrument

PC

Pressure transducer 0-300 psia

PT2

D1

D2

P1

P2

P3

PLA

TT2

Pressure transducer 0-50 psia

Pressure transducer 0-100 psid

Pressure transducer 0-200 psid

Pressure transducer 0-1000 psig

Pressure transducer 0-1000 psig

Pressure transducer 0-200 psig

Future

Future
12. Cabinets and Housings

Auxiliary Racks 1 and 2

Operator Control/Display Cabinet

PB/PT2 Motor Box

PB/PT2 Transducer Box

Resistor Box
Manufacturer and Mode1

Rosemount 1107A5AIF.A

Bell and Howell 367667-0100

Rosemount 1151DP6A12MB

Rosemount 1151DP7A12MB

Rosemount 1151GP8A12MB

Rosemount 1151GP8A12MB

Rosemount 1151GP7A12MB

Emcor, ESQ Series, Frame No, SFR 127A

Electronic Enclosures NBS Design, 213.06, $1 / 24 / 74$

Hoffman A-363012LP

Killark $\mathrm{XB}-12168$

Adalet X1F-030903 


\section{GLOSSARY AND SYMBOLS}

Symbols are given where used, and synonyms, symbols and alternate names are cross referenced.

Symbol

ACJET

Accessory Calibration for Jet Engine Tuneup, the acronym given to the software system designed and generated for this application [1].

\section{APPLICATIONS SOFTWARE}

The programs created and/or tallored to process

the requirements of a specific application. In

the ACJET system, these programs include: (1) the application user tasks through which all test stand control, data acquisition and data output occurs, and all fuel control test requirements are met; (2) the test executive which interfaces between the operating system RTOS and user application tasks, and which is primarily charged with processing test stand operator inputs; (3) the data base management tasks, since data base organization is applications oriented; and (4) the test stand automation device test programs.

AUXILIARY RACK 1, 2 ・

AUX RACK 1, 2 ・ $\cdot$

Designated cabinets housing stand automation hardware components.

\section{BOOST PRESSURE}

Stand fuel pressure, approximately 30 psig, generated by a centrifugal pump and needed to assure a positive pressure at the high pressure pump inlet.

BURNER PRESSURE

Air pressure signal fed to the fuel control which simulates air pressure at the engine compressor discharge/burner section. 
The fuel control burner pressure signal which actuates

the PB limiter. In the J52 engine, when the cotal

burner case differential pressure ( $\mathrm{PB}$ - amblent pressure)

exceeds a preselected maximum, the PB signal to the control burner pressure sensor assembly is reduced by bleeding through the limiter valve to ambient pressure, resulting in a reduction in fuel flow and engine speed which prevents combustion chamber pressure from approaching the maximum safe value.

\section{CARD FILE}

Chassis purchased from Technology Incorporated (TI) to house stand automation device interfaces purchased from TI.

A system for displaying alphanumeric information on the screen of a cathode ray tube. The system consists of a character generator, a video monitor and an interface to the processor.

That portion of the computer system which responds to a sequence of instructions for arithmetic and logical processing of data and for controlling or responding to external devices.

\section{CLOCK MODULE}

LFC

The computer system peripheral which includes a line

frequency clock used to provide time of day information and a precision interval clock which may be used as an interval timer.

COMPRESSOR DISCHARGE PRESSURE Se B BURNER PRESSURE.

Liquid bath temperature which simulates air temperature at the engine compressor inlet sensed by the fuel control TT2 bulb.

Air pressure signal fed to the fuel control which simulates air pressure at the engine compressor inlet. 
COMPUTER SYSTEM

The system comprised of the CPU and its display panel, the console teletypewriter, the fixed head disc, the line printer, the high speed paper tape reader/punch unit, and the device interfaces.

COMPUTER SYSTEM CABINET $1,2, \cdot \cdot \cdot$

Designated cabinets housing computer system components, and certain stand automation hardware components including the electronic counter(s), and $\mathrm{V} / \mathrm{F}$ converter(s) [CPU Cabinet 2 ...

CONTROL DRIVE SPEED

See FUEL CONTROL SHAFT SPEED.

NC

CPU, see CENTRAL PROCESSOR UNIT.

CPU CABINET $1,2 \cdots$

See COMPUTER SYSTEM CABINET $1,2 \ldots$

CRT, see CATHODE RAY DISPLAY SYSTEM.

DC TO FREQUENCY CONVERTER

$\mathrm{V} / \mathrm{F}$

The electronic unit which converts variable DC voltage level to a nominally proportional variable frequency pulse rate.

DEVICE CONTROLLER

See INTERFACE.

DEVICE INTERFACE

See INTERFACE。

DISC MEMORY

A bulk data storage device consisting of a rotating disc surfaced with a magnetic material. Data is stored on the surface as small magnetized areas arranged in circular tracks around the disc. Data on a given track is written or read sequentially as the disc rotates.

DISCHARGE FLOWRATE WF See FUEL CONTROL DISCHARGE FLOWRATE.

DISPLAY LAMPS

See DISPLAY LAMP PANEL. 
DISPLAY LAMP PANEL

A back-1ighted lamp assembly dedicated to status indication for automated parameters and hardware, and for error conditions for the processor and for operator command input.

\section{DISPLAYS}

See DISPLAY LAMP PANEL.

\section{DUAL DC/FREQUENCY MULTIPLEXER SYSTEM}

The portion of the prototype measurement system consisting of a dual multiplexer and a DC to frequency converter. One section of the multiplexer is used to switch DC signals to the converter. The other multiplexer section is used to switch AC signals, including the converter output, to the preset counter.

\section{DUAL MULTIPLEXER}

A device with two separate but interdependant reed relay switching units. Each unit connects multiple inputs, one at a time, to a common output.

\section{ELECTRICAL SERVICE UNIT}

A unit supplied with each teletypewriter consisting of a chassis containing electronic modules and power supplies necessary for controlling all the functions of the keyboard and typing unit.

ESU, see ELECTRICAL SERVICE UNIT.

EXPLOSION PROOF BOX OR ENCLOSURF.

A totally enclosed box, normally containing electrical or electronic equipment, constructed to withstand an explosion or combustion of a hazardous air/vapor mixture. Such boxes are normally of heavy construction and include mating closure surfaces sufficiently large to quench any products of combustion escaping to the outside world.

FUEL CONTROL

The jet engine accessory which meters or schedules fuel flow to the engine burners as required for the engine to deliver necessary thrust. Such thrust is dictated by the position of the pilot's power lever in the cockpit and by particular operating conditions of the engine, normally shaft speed, burner pressure, and compressor inlet air pressure and temperature. 
FUEL CONTROL DISCHARGE FLOWRATE

The metered fuel flowrate discharging from the fuel control and flowing to the engine burners.

FUEL CONTROL MANUAL/NORMAL TRANSFER

The process within the (J52 engine) fuel control whereby fuel control metering is transferred between two states, namely:

$$
\begin{aligned}
\text { Normal - } & \text { in which the metering functions are all } \\
& \text { automatic except for PLA input, and } \\
\text { Manual - } & \text { in which the metering is performed } \\
& \text { primarily through PLA input, with } \\
& \text { automatic compensation through PT2 } \\
& \text { only. }
\end{aligned}
$$

FUEL CONTROL SHAFT SPEED

Input shaft speed from the test stand variable speed drive which simulates engine accessory drive input.

FUEL CONTROL SUPPLY FLOWRATE

The fuel flowrate entering the fuel control from the test stand high pressure supply system. The engine high pressure fuel pump is simulated by scheduling and controlling WT as a function of NC speed.

HIGH SPEED PAPER TAPE READER/PUNCH UNIT

The computer system peripherial which retrieves/ (Punch) HSPTP stores data on paper tape.

HSPTP; HSPTR, see HIGH SPEED PAPER TAPE RF.ADER/PUNCH UNIT.

INLET BULB TEMPERATURE

See COMPRESSOR INLET AIR TEMPERATURE.

INTERFACE

Electronic circuitry necessary to provide electrical and logical compatibility between the computer processor and an external device.

LFC, see CLOCK MODULE.

LINE PRINTER

The high speed printing device to which the processor transmits a1l characters of a line as a unit.

LP, see LINE PRINTER. 
MANUAL CONTROL PENTANT STATION

See PENDANT STATION.

METERED FUEL FLOW

WF

See FUEL CONTROL DISCHARGE FLOWRATE.

MOTOR BOX

An explosion proof or air-purged enclosure in which one

or more step motors are mounted and housed.

Kn, see TEST STAND RELAYS,

\section{MULTIPLEXER}

MUX

The electronic unit or circuitry through which data

from several sources is selected to be transferred

over a common channel to a device that processes or

stores the data. The channel may be a single line

or a group of lines.

MULTIPLEXOR BUS (Interdata term)

MUX RUS

The channel through which the processor communicates with external devices. The channel consists of

16 bi-directional data lines, 8 control lines, 5

test 1 ines, and an initialization line.

MUX, see MULTIPLEXER.

MUX BUS, see MULTIPLEXOR BUS.

NC, see FUEL CONTROL SHAFT SPEED.

\section{NOZZLE DISCHARGE SYSTEM}

The system of restrictions and valves in the fuel control discharge circuit of the test stand console which simulates the engine burner nozzles, scheduling control discharge pressure as a function of flowrate WF.

OP PANEL, SEe OPERATOR CONTROL/DISPLAY PANEL.

OPERATING SYSTEM

A computer program which handles all the housekeeping or overhead tasks within a computer so that programs can be as independent from hardware details as possible. The operating system also sets standard conventions so that programs are compatible with one another [8]. 
OPERATOR CONTROL/DISPLAY PANEL

The primary device through which the stand operator communicates with the automated test system. This unit contains a TTY for command input and hardcopy printout, a CRT, and a display lamp panel.

OPERATOR PANEL

See OPERATOR CONTROL/DISPLAY PANEL.

OS, see OPERATING SYSTEM.

PENDANT STATION

The device through which the operator manua11v controls

individual step motors for parameters NC, PR and PT2, and future PLA and TT2.

PB, SCE BURNER PRESSURE.

PC, see BURNER PRESSURF. LIMITER PRESSURE.

PFC, see CLOCK MODULE.

PLA, see POWER LEVER ANGLE.

POT

Short form for potentiometer.

POWER LEVER ANGLE

PLA

The angular shaft position input to the fuel control which simulates the aircraft pilot's power lever command.

PRESET COUNTER

An electronic counter capable of having its counting mode and count time interval (pre)set under computer control.

PRESSURE REDUCING REGULATOR

A pressure regulator whose function is to throttle or reduce pressure in a fluid line.

PRESSURE REGULATOR

A flow device which produces a controlled output pressure in the range set by the supply and exhaust pressures and as a function of an input reference (force). Inputs include a mechanically loaded spring and/or a pressure signal. 
See CENTRAL PROCESSING UNIT.

PT2, see COMPRESSOR INLET PRESSURE.

PULSE PICKUP

A magnetic type transducer which generates electrical pulses when operating in a variable reluctance magnetic circuit; used in this system together with a spur gear on the NC speed shaft to generate the NC speed signal.

PURGE AIR

Air containing no hazardous vapors supplied at slight positive pressure to a box or enclosure, normally containing electrical or electronic equipment, located in a hazardous environment. With normal leakage, no hazardous vapors accumulate in the box and a safe operating environment is preserved.

READER/PUNCH

See HIGH SPEED PAPER TAPE READFR PUNCH UNIT.

RESISTOR BOX

An explosion proof or air purged enclosure housing certain pressure transducer load resistors.

RTOS

A real time operating system supplied by Interdata modified by NBS and adapted to hardware components used in this application. This system provides for interleaving the execution of a number of programs while still being responsive to the occurrence of real time events [9].

SPEED

See FUEL CONTROL DRIVE SPEED.

STAND

See TEST STAND.

STAND CONSOLE

See TEST STAND CONSOLE.

STAND CONTROL CABINET

See TEST STAND ELECTRICAL CONTROL CABINET.

STAND EMERGENCY STOP

The test stand console control used to de-energize the stand systems simultaneously. 
STAND VARIABLE SPEED DRIVE

The test stand subsystem which generates NC speed drive, including a DC motor driven at variable speed and the necessary controller electronics including speed feedback using a DC tachometer.

STEP MOTOR

A precision rotary, bidirectional positioning device which is driven by electrical pulse inputs. The output shaft position varies exactly in proportion to the number of input pulses in incremental angular steps.

STEP MOTOR DRIVE

See STEP MOTOR VARIABLE SPEED DRIVE.

STEP MOTOR VARIABLE SPEED DRIVE

VSD

Refers to terminology used by Responsyn (USM

Corporation) to denote the drive and control electronics unit generating step motor pulses. This electronics unit involves a manual pot adjustment to vary motor pulse or slew rate.

STEPPING MOTOR

SEe STEP MOTOR.

TELETYPE

See TELETYPEWRITER.

TELETYPEWRITER

A data terminal capable of sending and receiving alphanumeric information. It includes a typing or printer unit, and a keyboard unit.

\section{TEST STAND}

The assemb1y of equipment used to flow test jet engine fuel controls. It provides means to simulate and set engine operating conditions, and instrumentation to measure input and output parameter values. The primary parameters include NC, PB, PT2, TT2, WF, WT and various pressures and differential pressures.

TEST STAND CONSOLE

The part of the test stand containing the fuel flow circuitry, involving the supply and nozzle discharge systems, the actuator elements for simulating the engine conditions, the parameter measuring instruments, and the mounting pad for the fuel control. The console is always located in a hazardous environment for liquid hydrocarbons, as classified by the National Electric Code. 
TEST STAND ELECTRICAL CONTROL CABINET

The part of the test stand containing components such as the controller for the variable speed drive system, motor starter relays, and electronic control units and power supplies. This cabinet is always located in a nonhazardous location.

\section{TEST STAND RELAYS}

Kn

A set of relays under computer control with which the following stand functions or systems are controlled: stand emergency stop, fuel boost pump power, fuel high pressure pump power, vacuum pumps power, and stand variable speed drive DC controller power. Also, operation of the fuel control manual/normal transfer system is under computer control through relays in this set. Letter " $n$ " denotes relay number.

TOLERANCE

The assigned value which establishes the range to which an input parameter is controlled at its setpoint. For example, for a setpoint of 50 , control to within the range 49.95 to 50.05 would satisfy test requirements where 0.05 is the assigned tolerance.

TOTAL FLOW

See FUEL CONTROL SUPPLY FLOWRATE.

TRANSDUCER BOX

An explosion proof or air purged box housing one or more transducers.

TT2, see COMPRESSOR AIR INLET TEMPERATURE.

TTY, see TELETYPEWRITER.

VARIABLE SPEED DRIVE

A system capable of controlled operation over a range of speeds, between minimum and maximum RPM.

V/F, see DC TO FREQUENCY CONVERTER

VOLTAGE TO FREQUENCY CONVERTER

$\mathrm{V} / \mathrm{F}$

See DC TO FREQUENCY CONVERTER.

VSD, see STEP MOTOR VARIABLE SPEED DRIVE.

WF, see FUEL CONTROL DISCHARGE FLOWRATE.

WT, see FUEL CONTROL SUPPLY FLOWRATE. 
U.S. DEPT. OF COMM.

BIBLIOGRAPHIC DATA SHEET
1. PUBLICATION OR REPORT NO.

NBSIR 76-1051

4. TITLE AND SUBTITLE

A Prototype Automated Test System for J52 Engine Fuel Controls

Part 1. Hardware Systems Sumary

\section{AUTHOR(S)}

David W. Baker, Alfred L. Koenig, and Victor Brame, Jr. 9. PERFORMING ORGANIZATION NAME AND ADDRESS

NATIONAL BUREAU OF STANDARDS

DEPARTMENT OF COMMERCE

WASHINGTON, D.C. 20234

2. Gov'c Accession No.

3. Recipient's Accession No.

5. Publication Date April 1976

6. Performing Organization Code

8. Performing Organ. Report No. NBS 213,06

10. Project/Task/Work Unit No. 2130462

11. Contract/Grant No.

13. Type of Report \& Period Covered

Final

14. Sponsoring Agency Code NAVAIR

15. SUPPLEMENTARY NOTES

16. ABSTRACT (A 200-word or less factual summary of most significant information. If document includes a significant bibliography or literature survey, mention it here.)

Hardware subsystems are described which have been developed by NBS and added to a manual controlled test stand, CID Model 15730, and which together comprise the test system. Digital computer control is used which incorporates a vendor supplied real time software operating system, extended and adapted to the hardware subsystems by NBS. Then applications software is complete, the system will be sultable for production testing of $\mathrm{J} 52$ engine fuel controls. Test parameters under computer control are shaft speed, burner air pressure and compressor inlet pressure, along with systems for measurement of fuel control discharge and supply flowrates and eight fuel control pressures. The operator controls the test through a subsystem equipped with a CRT, a teletypewriter, and a set of back-1ighted display lamps. The hardware and software systems have been designed for multistand control, and hardware requirements for control of up to five stands by one computer are discussed briefly.

17. KEY WORDS (six to twelve entries; alphabetical order; capitalize only the first letter of the first key word unless a proper name; separated by semicolons) Automated test equipment; Automated test equipment for jet engine fuel controls; fuel control test equipment; Digital computer controlled test equipment; Jet engine Minicomputer applications; Minicomputer controlled test equipment: Supervisory control

18. AVAILABILITY Unlimited

प For Official Distribution. Do Not Release to NTIS

Order From Sup. of Doc., U.S. Government Printing Office Washington, D.C. 20402, SD Cat. No. C13

\begin{tabular}{|l|l|}
\hline $\begin{array}{l}\text { 19. SECURITY CLASS } \\
\text { (THIS REPURT) }\end{array}$ & 21. NO. OF PAGES \\
UNCL ASSIFIED & \\
\hline $\begin{array}{l}\text { 20. SECURITY CLASS } \\
\text { (THIS PAGE) } \\
\text { UNCLASSIFIED }\end{array}$ & 22. Price \\
\hline
\end{tabular}


